\title{
CULTURA AFRO-BRASILEIRA NOS CADERNOS DE EDUCAÇÃO FÍSICA DO ENSINO FUNDAMENTAL II.
}

Letícia Queiroz Citta ${ }^{1}$, Wagner Aparecido Caetano ${ }^{1}$, Arilda Inês Miranda Ribeiro ${ }^{2}$, Carlos Augusto de Carvalho Filho. ${ }^{1}$

Universidade do Oeste Paulista - UNOESTE. Curso de Educação Física, Presidente Prudente - SP. ${ }^{2}$ Universidade Estadual Paulista - FCT/UNESP, Presidente Prudente - SP. Grupo de Pesquisa em Educação, Cultura, Memória e Arte (GPECUMA), Presidente Prudente - SP. E-mail: wagner@unoeste.br.

\section{RESUMO}

Este trabalho propõe uma discussão e reflexão acerca da Lei 10.639/03, que traz a obrigatoriedade do ensino de cultura afro-brasileira nos níveis de Ensino Fundamental II e Médio. Para tanto, contextualizamos os fatores históricos relacionados à população negra no Brasil, desde a inferiorização da cultura durante o período de escravidão no Brasil colonial, às consequências sociais materializadas na contemporaneidade em múltiplas vertentes. Em seguida, discutimos a capacidade da educação física escolar, enquanto disciplina do movimento e de construção de valores, na contribuição efetiva da referida Lei, por meio do resgate aos valores culturais deste povo que se constitui a maioria étnica do nosso país e que participou e participa efetivamente da construção da identidade nacional. Para finalizar, apresentaremos uma análise e discussão sobre os conteúdos da cultura afro-brasileira encontrados no Caderno do Aluno do Ensino Fundamental II, disponibilizado pelo governo do Estado de São Paulo. A metodologia adotada segue os pressupostos da pesquisa qualitativa, visto que suas deduções são procedentes da análise dos materiais didáticos presentes em unidades escolares do Estado de São Paulo.

Palavras-chave: Lei 10.639, Cultura Afro-brasileira, Educação Física Escolar.

\section{AFRO-BRAZILIAN CULTURE IN THE NOTEBOOKS OF PHYSICAL EDUCATION BASIC EDUCATION II.}

\begin{abstract}
This work proposes a discussion and reflection about the Law 10.639/03, which brings the mandatory teaching of african-brazilian culture in the levels of Middle and Secondary School. However, we contextualize the historical factors related to the black population in Brazil, since the degradation of their culture during the period of slavery in colonial Brazil, the social consequences materialized in contemporary multiple strands. In this context we discuss the capacity of school physical education - as a discipline of movement and building values - to contribute to the execution of the said Law, rescuing cultural values of the people who constitute the ethnic majority in our country and who participated and participates effectively in the construction of national identity. Finally, we present an analysis and discussion about of contents african Brazilian culture found in the Student Notebook Secondary School, made available by the state government of São Paulo. The methodology follows the assumptions of qualitative research, since their deductions are coming from the analysis of teaching materials in school units of the State of São Paulo.
\end{abstract}

Keywords: Law 10.639/03, Afro - Brazilian, School Physical Education. 


\section{INTRODUÇÃO}

A implantação da Lei 10.639, em 9 de Janeiro de 2003,

altera a Lei $\mathrm{n} 09.394$, de 20 de dezembro de 1996, que estabelece as diretrizes e bases da educação nacional, para incluir no currículo oficial da Rede de Ensino a obrigatoriedade da temática "História e Cultura Afro-Brasileira", e dá outras providências. (BRASIL, 2003, s.p)

Tais providências referem-se à inclusão dos artigos: 26-A, 79-A e 79-B. Para esta pesquisa é de maior relevância o Art. 26A, inciso 2ㅇ, o qual estabelece que "os conteúdos referentes à História e Cultura Afro-Brasileira serão ministrados no âmbito de todo o currículo escolar ${ }^{6}$, em especial nas áreas de Educação Artística e de Literatura e História Brasileira" (BRASIL, 2003, s.p.).

Considerando toda historicidade dos fatos relacionados ao negro desde o período colonial em nosso país, entendemos que devido à opressão e repressão característicos da escravidão que estes sofreram, houve por parte dos colonizadores e escravocratas, uma inferiorização dos valores culturais, políticos e religiosos daqueles que são procedentes da etnia africana.

A referida Lei (Lei 10.639) eclodiu como proposta de reparar os danos causados ao povo negro durante todo processo de construção de nossa sociedade, sugerindo o reconhecimento da contribuição históricosocial dos africanos e seus descendentes na história do Brasil. Contudo, é necessário pontuar que apesar de sua vigência datar o ano de 2003, significativa parte dos alunos possui conhecimento deficitário em relação a esta temática.

É neste sentido que pautamos a hipótese deste trabalho de pesquisa, ou seja, é possível que a Lei (Lei 10.639) não tenha sido efetiva de maneira a abranger todos os alunos e professores, seja por falta de incentivo do Estado, ou mesmo por falta de formação ou preparação específica dos docentes, como também por pura resistência ao conteúdo exigido pela temática.

Sabemos que segundo a Lei 10.639/03, a obrigatoriedade do ensino de História e Cultura Afro-Brasileiras concentrase em especial nas disciplinas de Educação Artística, Literatura e História Brasileira estas diretamente mencionadas - por inferência do art. 26-A, inciso 2으, entendemos a coparticipação de todas as outras disciplinas não citadas.

Deste modo, a disciplina de Educação Física, enquanto promotora de cultura - uma vez que é criada e modificada pelo homem em tempo e espaços distintos, deixando claro seu caráter antropológico (DAOLIO, 2009) se constitui, entre outras disciplinas, em um

\footnotetext{
${ }^{6}$ Grifo dos autores.
} 
significativo meio para viabilizar o que alude à referida Lei.

Em meio a esta contextualização e teorização sobre o assunto, propomos uma discussão acerca do tema, uma vez que levantamos aspectos relevantes, tais como: a inferiorização da cultura negra durante o período de escravidão e suas consequências na contemporaneidade, bem como a capacidade da educação física - enquanto disciplina de construção de valores - em resgatar a importância e consciência da cultura negra em nosso país, por meio da inserção de manifestações culturais artísticas, musicais e corporais, no projeto pedagógico do ensino fundamental.

Para tanto, analisamos o material didático fornecido pelo Estado de São Paulo, sendo a investigação limitada aos Cadernos da disciplina de Educação Física do Ensino Fundamental II- Caderno do Aluno e do Professor.

Por meio da Lei 10.639/03 sabemos que fica estabelecida a obrigatoriedade do ensino sobre a cultura afro-brasileira, desta maneira, averiguamos estes materiais a fim de encontrar a temática enfatizada nos conteúdos propostos.

Enfatizamos que o caráter desta pesquisa é de sentido qualitativo, visto que suas deduções são procedentes da análise dos materiais didáticos presentes em unidades escolares. Assim sendo, é pertinente esclarecermos a metodologia adotada neste trabalho grafando os dizeres de Patton que discorrem sobre a dimensão de campo da pesquisa qualitativa:

[...] descrições detalhadas de situações, eventos, pessoas, interações e comportamentos observados; citações literais do que as pessoas falam sobre suas experiências, atitudes, crenças e pensamentos; trechos ou íntegras de documentos, correspondências, atas ou relatórios de casos (PATTON apud ALVES-MAZZOTTI, 1999, p. 132).

Apresentar-se-á uma análise e resultados dos dados e conteúdos evidenciados nestes materiais relacionados ao tema: Cultura Afro-Brasileira.

\section{O negro no Brasil e as políticas afirmativas}

Pautando-se na Lei 10.639/03 e embasados em Oliveira (2012), entendemos que para a abordagem do presente tema, torna-se necessário uma breve fundamentação acerca da historicidade dos afrodescendentes desde os primórdios do período colonial, em interface com contexto do desenvolvimento histórico e sociocultural do país. Compreendendo o etnocentrismo europeu como provável causa da origem do racismo, evidenciando suas manifestações, implicações e consequências, além de interpretação de políticas de ações 
afirmativas $^{7}$, como iniciativas ao processo de valorização de um povo fundamental no processo de construção da nação brasileira: O negro.

O racismo não tem origem apenas na opressão e trabalho escravo vivenciado pelos negros, mas também na miscigenação gerada no processo de colonização do Brasil.

Em meados do século XIX, tal questão incomodava tanto os europeus, que estes discursavam sobre uma "decadência" racial, resultante do cruzamento das raças, que para eles deram origem ao prejuízo da "qualidade física e moral", isto por que as raças já não eram "puras" como as "primitivas". Discursavam ainda que a miscigenação das raças determinava a inferioridade dos miscigenados frente aos indivíduos de raça pura. (AGASSIZ apud SILVA, 2012, p.197-198)

Quanto à origem da dificuldade social enfrentada pelo povo negro no Brasil, concordamos com Neri (2010), quando afirma que:

A história do Brasil é contada por muitos e de diversas formas, no entanto a história do negro no nosso país, sempre foi de sofrimento e luta, por se achar instalado no Brasil um sistema que escravizava os povos vindouros (negros) da África, pra manter uma

\footnotetext{
7 Políticas de ações afirmativas: foram criadas pelo governo e possuem caráter reparatório, ou seja, sua finalidade é promover a igualdade de oportunidades, sendo um meio de compensar as perdas e desigualdade consequentes de um processo discriminatório de origem étnico-racial, religiosa ou mesmo de gênero (OLIVEIRA, 2012).
}

burguesia de brancos da Europa. A situação que os negros encontraram no Brasil foi de repressão, opressão e trabalho escravo, ambiente próprio para desenvolver no povo um ar de inferioridade, na cultura, na religião, na vida em geral, daí o porquê de hoje se ver a luta por resgatar os valores negros[...](NERI, 2010, s.p).

Após a abolição os negros enfrentaram diversas dificuldades. Para Dias e Ricardo (2010), após a Lei de abolição da escravatura no Brasil, assinada pela princesa Isabel em 1888, a vida do negro ficou marcada pelo desemprego, analfabetismo e falta de moradia que os condicionaram a viver à margem da sociedade, em meio à pobreza e falta de oportunidades. (DIAS; RICARDO, 2010, s.p)

No continente americano, as primeiras manifestações de políticas de ações afirmativas $^{8}$, procedem de meados do século $X X$, em especial após a implementação da Lei dos Direitos Civis, nos Estados Unidos, resultando de lutas de grupos organizados da sociedade civil, principalmente de movimentos negros liderados por Martin Luther King e Malcolm X (OLIVEIRA, 2012, p.29).

\footnotetext{
${ }^{8}$ Sendo que“internacionalmente, as ações afirmativas tiveram origem na Índia, na década de 1940 , com a criação do primeiro sistema de cotas em benefício de representantes de castas inferiores, que por motivos religiosos, tinham grande atraso social e econômico". (OLIVEIRA, 2012, p.30).
} 
Segundo Abreu e Mattos (2008, p.56), a primeira iniciativa de ações afirmativas no Brasil e em âmbito escolar ocorreu no ano de 1996, quando aprovado pelo MEC, os Parâmetros Curriculares Nacionais (PCNs) introduziu ao ensino conteúdos relacionados à história africana, precedendo e contribuindo para a resolução e instituição das "Diretrizes Curriculares Nacionais para a educação das relações ético-raciais e para o ensino de historia e cultura afro-brasileira e africana" que:

[..]foram aprovados pelo Conselho Nacional de Educação (CNE) em março de 2004 e homologados pelo Ministério da Educação (MEC) em junho do mesmo ano. A resolução foi resultante do Parecer CNE/CP3/2004, que teve como relatora a conselheira Petronilha Beatriz Gonçalves e Silva, da Câmara de Educação Superior do CNE. As "Diretrizes" visam atender à Lei no 10.639/2003, que estabeleceu obrigatoriedade do ensino de história e cultura afrobrasileira e africana nas escolas do país. (ABREU; MATTOS, 2008, p.5-6)

Para os referidos autores tais documentos "têm hoje força de lei e representam uma vontade de democratização e correção de desigualdades históricas na sociedade brasileira". (ABREU; MATTOS, 2008, p.6).

Lorenzet e Carpenedo (2012, p.27) afirmam que documentos legais:

[...]não deixam de ser programas afirmativos para suprir necessidades emergentes evidenciadas e que possivelmente já estavam amparadas legalmente, mas no entanto, não eram cumpridas criando, ou sendo coniventes com situações de desigualdade, onde deveria haver a supremacia do direito constitucional inalienável.(LORENZET; CARPENEDO, 2012, p.7).

Por isto, para que se mantenha a estrutura capitalista, tais políticas não vêm ao encontro das necessidades sociais e sim como mecanismo para acalmar movimentos e manter a ordem, por meio de aparelhos repressivos e ideológicos do Estado. Sendo assim, cabe a crítica de Platt ao identificar a ineficiência das políticas públicas em relação à temática:

[...] políticas sociais emanadas pelo Estado, desde a implantação do sistema capitalista, é míope ao raio das atividades que deverão atingir o público alvo (os desassistidos, os desafiliados sociais), da mesma forma que utiliza meios que não alcançam a população maciçamente de forma a projetar a solução 
na radicalidade de seus problemas. (PLATT s/a, p. 13-16).

Entendemos que as políticas sociais afirmativas e de caráter inclusivo, acabam por excluir boa parte dos sujeitos sociais, pois a complexidade da questão vai além do reparo e/ou compensação das desigualdades e falta de oportunidades geradas durante todo o processo de construção do país, chegando a problemas estruturais, causados pelo próprio sistema vigente.

Segundo dados do IBGE 2010, a população negra cresceu cerca de 1,4\% comparada a 2000. Sendo assim, nos dias atuais, o percentual de negros na população brasileira está por volta de 7,6\%, ou seja, 15 milhões de pessoas são consideradas negras em nosso país.

Entendendo a miscigenação como uma questão fundamental para a compreensão sobre a composição da população brasileira, percebemos que alguns indivíduos mesmo não sendo ou não se considerando puramente negros, possuem alguma descendência genética desta etnia, desta maneira, o percentual aumentaria para $50,7 \%$ (IBGE 2010), se considerarmos que os que se denominam pardos - 43,1\% - (IBGE 2010), possuem uma significativa carga genética da etnia negra (ALVES, 2010).

É por isto que existe a importância de reconhecimento de uma dívida histórica, pois além da influência no processo de construção social, cultural e econômica, o negro hoje compõe grande parte da população brasileira e ainda sofre um maior grau de preconceito (LEITE, 2012, s.p.) - comparado aos outros segmentos populacionais - uma vez que este se manifesta em esfera social e econômica.

\section{Escola e disciplina de Educação Física: meios} para a efetivação da Lei 10.639/03.

Orientados por este contexto histórico de luta e superação, entendemos que a escola, enquanto "lócus" do processo de desenvolvimento e das potencialidades humanas - em aspecto físico, social e mental - deve proporcionar vivências e/ou experiências que contribuam para a construção e consolidação de valores e conceitos individuais, sociais e culturais (NEIRA, 2003).

Assim, a escola se constitui em espaço propício para a aplicação de ações concretas que estimulem o reconhecimento cultural e valoração da etnia negra, contribuindo para a construção de novos conceitos e valores, para que as novas gerações possam agir de forma positiva e igualitária reconhecendo as contribuições da etnia africana na culinária, manifestações artísticas, religiosas, musicais, científicas, literárias e corporais do povo brasileiro.

Pautados nas reflexões de Neira (2003), inferimos que a Educação Física - 
enquanto disciplina do movimento - pode ser um meio, legítimo e institucionalizado, de oportunizar vivências e/ou experiências que venham ao encontro dos objetivos supracitados, tanto por sua capacidade de promover cultura, quanto pelo seu potencial em estimular o desenvolvimento integral de um indivíduo.

Cabe ressaltar que, historicamente, a Educação Física priorizava o aspecto e desenvolvimento biofisiológico do indivíduo, porém, a partir do final dos anos 70 e início dos anos 80, novas concepções surgiram como enfrentamento ao método tecnicista, esportivista e tradicional da Educação Física escolar. Entre estas concepções estão os PCN (Parâmetros Curriculares Nacionais), que pressupõe a disciplina de Educação Física, basear-se também na Psicologia e Sociologia (DARIDO E RANGEL, 2008), uma vez que objetiva, por meio de uma abordagem crítico-superadora, uma prática que rompa com paradigmas tradicionais e tecnicistas, atingindo dimensões culturais, sociais, políticas e afetivas de um indivíduo ou grupo (BRASIL, 1998).

Este artigo propõe uma discussão a acerca da atuação da disciplina de Educação Física, em ações plausíveis à efetivação da Lei 10.639/03, atendendo, assim, essa nova abordagem legitima pelos PCNs.

Da mesma forma pensa Oliveira (2012) sobre a abrangência temática e a contribuição que a disciplina de Educação Física pode oferecer às políticas afirmativas, permitindo:

[...] evidenciar a importância da constante movimentação e da exploração máxima do ambiente. Essa atividade tem que se remeda ter às características individuais do aluno, de maneira que seja significativa para o seu desenvolvimento orgânico e funcional, além de buscar a superação e valorização em diferentes dimensões, como a cultural, social, política e afetiva. Numa perspectiva crítica emancipatória, a educação física deve procurar desenvolver três níveis de competências nos alunos: as técnicas, as sociais (interação) e as linguísticas. (OLIVEIRA, 2012, p.47).

E continua:

Nessa expectativa, a educação física valoriza-se crítica, para contribuir com a realidade do país, em resgate à cultura corporal do movimento da população (MOREIRA, 2008), a qual possibilita um trabalho interdisciplinar. Ainda, no ensino da história e cultura afro-brasileira e africana, mediante a implementação da Lei no 10.639/03, a temática da pluralidade cultural afro passou a ser valorizada, enriquecendo os conteúdos que possam ser desenvolvidos nas escolas. 
Nesse sentido, as vivências podem propiciar a preservação, o respeito e a valorização da nossa cultura, diminuindo posturas racistas, a caminho da igualdade racial (OLIVEIRA, 2012. p.47).

Oliveira (2012) justifica a relevância do tema, assim como insere a disciplina de Educação Física neste contexto de interferir com ações afirmativas, estando diretamente ligada ao problema em questão.

\section{Analise ao Caderno do Aluno e do Professor} do Estado de São Paulo: Resultados e

\section{Discussões}

O Caderno do Aluno e do Professor surgiu como proposta pedagógica criada em 2007 e implementada em 2008 nas escolas públicas do Estado de São Paulo, sendo organizados por bimestres e disciplinas (OLIVEIRA, 2012, p. 57).

Enquanto o Caderno do Aluno apresenta breves e sucintas introduções aos conteúdos, bem como propostas de pesquisas e exercícios a serem realizados de acordo com o tema, o Caderno do Professor faz uma contextualização teórica a cerca de cada tema a ser trabalhado, além de propor atividades por meio de "orientações didáticopedagógicas e traz como base o conteúdo do Currículo Oficial do Estado de São Paulo" (SÃO PAULO, 2013c, p. 3).
Tendo em vista o objetivo desta pesquisa, recolhemos e analisamos estes Cadernos referentes à disciplina de Educação Física, especificamente entre o 60 e 9 ano do Ensino Fundamental Público do Estado de São Paulo.

Ao analisar este material, evidenciamos conteúdos que contemplam a influência da cultura afro-brasileira em dois momentos, tanto no caderno do 1 o bimestre do 7 ㅇ ano ${ }^{9}$, como também no 1 으 bimestre do 9o ano $^{10}$ do Ensino Fundamental II.

O Caderno do Aluno do 70 ano apresenta conteúdos relacionados ao Tema: "Atividade Rítmica - Manifestações e Representações da Cultura Nacional" (SÃO PAULO, 2013a, p. 16). Por meio de uma breve introdução, destaca a pluralidade da cultura rítmica nacional, citando os povos e etnias que influenciaram a sua construção, porém sem especificar as origens dos ritmos nacionais. A proposta é que os próprios alunos pesquisem sobre os principais ritmos brasileiros, evidenciando suas origens, grupos étnicos aos quais estão associados, bem como o Estado do país onde ser concentram, além de possíveis relações entre os ritmos pesquisados com religiões ou crenças (SÃO PAULO, 2013a, p. 17).

Posteriormente há a sugestão de um exercício de associação, onde o aluno,

\footnotetext{
${ }^{9}$ Capítulo 2: Atividade Rítmica - Manifestações e Representações da Cultura Rítmica Nacional, p. 16.

${ }^{10}$ Capítulo 1: Luta - Capoeira, p. 3.
} 
pautado em tudo o que pesquisou, deve unir as imagens apresentadas às nomenclaturas de manifestações rítmicas que elas representam: Forró; Quadrilha; Siriri; Catira; Carimbó; Bumba meu Boi; Chula; Frevo (SÃO PAULO, 2013a, p. 18-19).

Por fim, outro exercício é proposto onde o aluno deve descrever a região geográfica a qual pertence cada ritmo supracitado (SÃO PAULO, 2013a, p. 20).

Enquanto isto, o Caderno do Professor do 7을 ano do Ensino Fundamental II, também apresenta uma introdução e contextualização ao tema e propõe possibilidades interdisciplinares ${ }^{11} \mathrm{com}$ as disciplinas de:

História, Geografia, Arte, Língua Estrangeira (Inglês ou Espanhol) e Língua Portuguesa, na medida em que envolve conteúdos relacionados às manifestações rítmicas das diferentes regiões do Brasil e seus grupos étnicos majoritários (SÃO PAULO, 2013c, p.33).

Orienta os conteúdos e temas a serem trabalhados, bem como as competências e habilidades a serem exploradas, além de sugerir os recursos a serem utilizados para a

\footnotetext{
${ }^{7} \mathrm{O}$ termo interdisciplinaridade surge em âmbito educacional por meio das LDB (Leis de Diretrizes e Bases da educação), desde o final dos anos 60, se constituindo em proposta pedagógica nos PCN (Parâmetros Curriculares Nacionais). Tal termo pressupõe um trabalho organizado e articulado, por meio de ações coordenadas entre as disciplinas que compõe o currículo escolar, visando um objetivo e/ou interesse comum (CARLOS, s/a, p.1-3).
}

presente finalidade (SÃO PAULO, 2013c, p.33).

Em suma, propõe atividades para que o professor explore e conheça a realidade de seus alunos, quanto à vivência de ritmos, como também dinâmicas introdutórias ao tema, situações de aprendizagem que permitam a vivência de ritmos em aula, além das pesquisas e exercícios já mencionados previamente no relatório sobre o Caderno do Aluno (SÃO PAULO, 2013c, p. 33-39).

Com isto, visto que a construção da cultura rítmica nacional foi influenciada por vários povos e etnias, tanto do período colonial quanto do período de migração, entendemos que o conteúdo do caderno, indiretamente contribui para uma iniciativa de valoração e reconhecimento da raça negra no processo de construção da cultura nacional. Quando sugere a pesquisa dos principais ritmos brasileiros e suas origens, possibilita ao aluno o conhecimento de que o Carimbó, Frevo, Samba e Catira, são ritmos criados sob influências de costumes e manifestações do povo africano. E quando sugere possibilidades interdisciplinares no Caderno do Professor, orienta uma ação que certamente facilitaria uma melhor compreensão sobre o tema, por parte dos alunos.

O Caderno do Aluno referente ao 1 은 bimestre do 9o ano aborda uma das influências e contribuições dos africanos à 
nossa cultura. Com o Tema: "Luta - Capoeira” (SÃO PAULO, 2013b, p. 3), introduz conteúdos relacionados a esta manifestação cultural. Por meio de uma introdução descreve sobre sua origem; motivação para a sua criação em meio à escravidão; sua caracterização como jogo, luta ou dança; e a descrição dos instrumentos musicais utilizados (SÃO PAULO, 2013b, p. 3-4).

Em seguida, sugere aos alunos uma pesquisa sobre música e/ou cantigas de roda de Capoeira (SÃO PAULO, 2013b, p. 4). Posteriormente há um texto descritivo e explicativo sobre como exercitar a ginga (SÃO PAULO, 2013b, p. 7). Na sequência propõe um desafio, para que aluno associe as imagens dos movimentos de capoeira às nomenclaturas encontradas em um caçapalavras (SÃO PAULO, 2013b, p. 8-10). Lembrando que em nenhum momento há algum texto explicativo sobre os movimentos de capoeira e seus nomes, ficando esta parte exclusivamente de responsabilidade do professor. Por fim, o caderno aborda aspectos explicativos sobre a diferença entre a Capoeira Angola e Regional (SÃO PAULO, 2013b, p. 11).

O Caderno do Professor, referente ao 10 bimestre do 9a ano, após introduzir e contextualizar sobre o assunto sugere um trabalho interdisciplinar com as disciplinas de História e Geografia, visando atender a Lei 10639/03 (SÃO PAULO, 2013 d, p. 8).
Entre as atividades propostas estão: para o conhecimento prévio sobre o que os alunos conhecem a respeito da capoeira; explicação sobre sua origem e dinâmica; exemplificação dos movimentos e suas nomenclaturas; - apresentação dos instrumentos musicais utilizados; sugestões de vivência de roda de capoeira em aula; explicação sobre as diferenças entre Capoeira Angola e Regional; - Por fim avaliação sobre o conteúdo (SÃO PAULO, 2013 d, p. 8-27).

\section{Entendendo} que contemporaneamente a Capoeira seja considerada um dos principais meios de difusão da cultura e língua brasileira pelo mundo. Ao analisarmos os Cadernos do Aluno e do Professor do Ensino Fundamental II, percebemos que tal manifestação cultural, artística e em "processo de esportivização" (OLIVEIRA, 2012, p.76), é abordada de maneira sucinta frente à magnitude de sua importância, pois para uma real efetivação da Lei 10.639/03, existem vários aspectos a serem aperfeiçoados, desde recursos matérias e técnicos, à formação conceitual dos gestores e professores, sobre o valor da contribuição dos negros na construção de nossa cultura.

Após a avaliação destes cadernos, torna-se relevante citar a pesquisa realizada por Oliveira (2012), que após a aplicação de um questionário a professores da rede pública estadual de Santo André, conclui que 
a manifestação destes conteúdos encontra dificuldades frente à falta de estrutura, formação e informação (OLIVEIRA, 2012, p.96).

\section{CONCLUSÃO}

Em meio a toda contextualização histórica e levantamento de informações inerentes à temática em questão/problema da pesquisa, percebemos que a ineficiência em efetivar a Lei 10639/03, resulta de aspectos estruturais, conceituais, matérias e técnicos.

Uma vez que a referida Lei se constitui em Política de Ação Afirmativa em resposta à pressão de movimentos sociais negros, também se estabelece como mecanismo de controle da massa e manutenção da ordem, pois, a única iniciativa em questão é a inclusão da temática nos cadernos didáticos oferecidos pelo próprio Estado, estando os Gestores e Professores sujeitos a escassez de processos formativos, recursos materiais e técnicos que os impedem de aplicar aulas que realmente atendam as necessidades e déficits culturais.

Reconhecemos a disciplina de Educação Física como meio possível para estimular de forma contínua e gradual a formação do sujeito social, seus valores e sua cultura, uma vez que é orientada a romper com padrões tradicionais, estimulando uma reflexão crítico-superadora dos alunos, por meio de uma prática que atenda as necessidades físicas, mentais e sociais, sendo assim, pode colaborar para a superação de problemas de inferiorização e preconceitos, como também para o reconhecimento da etnia afro e suas contribuições para a formação do povo brasileiro.

Porém, cabe ressaltar que embora os cursos de graduação em Educação Física venham inserindo em sua grade curricular a disciplina de capoeira, além das atividades rítmicas e expressivas, como iniciativa para a formação de professores, visando atender a Lei $(10.639 / 03)$ imposta, devemos nos lembrar dos profissionais atuantes no mercado de trabalho e até mesmo os que estão no fim da carreira, que mesmo com o programa de formação continuada, não adquirem conhecimentos ou mesmo nem se interessam pela temática. 0 que pressupõe que há formadores que desconhecem, por motivos variados, a importância e o significado de tal trabalho.

Percebemos que nos Cadernos do Professor há uma clara motivação à interdisciplinaridade (SÃO PAULO, 2013c, p.33); (SÃO PAULO, 2013d, p. 8), nos remetendo à ideia de que para a efetivação deste diálogo interdisciplinar deve ocorrer uma contemplação das áreas a serem abordadas em outras disciplinas, possibilitando ao aluno uma direção e uma cobrança, para com as outras disciplinas, 
sobre o que gostariam de relacionar, aprofundar ou explicitar com maior clareza. A interdisciplinaridade deve acontecer na prática, orientada claramente pela teoria.

Sendo assim, acreditamos que por mais que nas aulas de Educação Física seja possível um trabalho que vise à efetivação da Lei $(10.639 / 03)$ - considerando que sua prática atenda dimensões além da esfera biofisiológica, proporcionando o estímulo ao desenvolvimento do indivíduo em âmbito cultural, político e social - existe a necessidade de uma melhor articulação entre as várias áreas do conhecimento, para que juntas possam projetar o que "deveria" ser o principal objetivo da escola: formação integral do indivíduo, ou seja, em aspecto físico, sócio-afetivo, cultural e cognitivo. Para que assim a Lei (10.639/03) seja atendida de forma consolidada, visto que um trabalho conjunto entre as disciplinas proporcionaria uma maior solidificação e continuidade dos conteúdos.

Quanto ao conteúdo encontrado nos Cadernos analisados, percebemos que embora sucinta, existe uma orientação e proposta condizente a temática, porém, o que se percebe é uma teorização descompromissada, visto que a falta de recursos técnicos e matérias limitam uma ação profissional que a efetive.

Pontuamos ainda a necessidade de projetar tal conteúdo em todos os anos do ensino fundamental II, mesmo porque, as manifestações afro-brasileiras ocorrem em vários âmbitos da cultura, o que necessita serem exploradas com mais ênfase e qualidade. Portanto, carece de um período maior que um bimestre em dois anos do ensino fundamental II,- 10 bimestre/7음 ano; 10 bimestre/9o ano) - possibilitando uma continuidade aos conteúdos de maneira progressiva, permitindo que tenham sentido e solidificação no processo ensinoaprendizagem, construção de identidade nacional e efetivação de ações positivas.

Mesmo havendo uma obrigatoriedade do ensino de cultura afro-brasileira, o Estado não criou mecanismos que mensurem o processo de efetivação da Lei, por isso a falta de compromisso com este conteúdo é tão evidente.

Concluímos então, que um trabalho coletivo e interdisciplinar visando à efetivação da Lei em questão, será possível apenas quando muitos preconceitos, paradigmas e individualismo forem superados. Por ser uma questão social em padrão estrutural, esta temática é um grande desafio, pois além de envolver fatores políticos e sociais, depende de conceitos pessoais, individuais e subjetivos.

\section{REFERÊNCIAS}

ABREU, M.; MATTOS, H. Em torno das "Diretrizes curriculares nacionais para a educação das relações étnico-raciais e para o 
ensino de história e cultura afro-brasileira e africana": uma conversa com historiadores. Estudos Históricos, Rio de Janeiro, v. 21, n. 41, p. 5-20 jan./jun. 2008.

ALVES, J. E. D. A definição cor/raça do IBGE. Disponível em: <http://www.ecodebate.com.br/2010/06/28 /a-definicao-de-corraca-do-ibge-artigo-dejose-eustaquio-diniz-alves/>. Acesso em: 13 maio 2014.

ALVES-MAZZOTTI, A. J. O método nas ciências sociais. In: ALVES-MAZZOTTI, J. A.; GEWANDSZNAJDER, F. 0 método nas ciências naturais e sociais: pesquisa quantitativa e qualitativa. 2. ed. São Paulo: Pioneira, 1999.

BRASIL. Lei no 10.639, de 9 de janeiro de 2003. História e Cultura Afro-Brasileira.

BRASIL. Ministério do Planejamento, Orçamento e Gestão. Instituto Brasileiro de Geografia e Estatística. Contagem Populacional. Disponível em: <http://www.ibge.gov.br>. Acesso em: 12 Out. 2013.

BRASIL. Secretaria de Educação Fundamental. Parâmetros curriculares nacionais: Educação Física/Secretaria de Educação Fundamental. Brasília: MEC / SEF, 1998.

CARLOS, J. G. Interdisciplinaridade do Ensino Médio: Desafios e Potencialidades. Disponível em: <http://www.miniweb.com.br/educadores/a rtigos/pdf/interdisciplinaridade.pdf>. Acesso em: 10 maio 2014.

DAOLIO, J. Antropologia, Cultura e Educação Física Escolar: Considerações a respeito do artigo de Moura e Lovisolo. Revista Brasileira de Ciência do Esporte, vl. 3, n. 1, p.179-192. set. 2009.
DARIDO, S. C.; RANGEL, I. C. A. Educação física na escola: implicações para a prática pedagógica. Rio de Janeiro: Guanabara Koogan, 2008.

DIAS, K. A.; RICARDO, P. R. O Estado Brasileiro tem uma dívida histórica com o povo negro. Disponível em: < www.egocosmos.com/arquivos/5.pdf >. Acesso em: 12 fev. 2013.

LEITE, M. P. Preconceito racial e racismo institucional no Brasil. Disponível em: <<http://www.diplomatique.org.br/artigo.ph p?id=1202 > . Acesso em: 12 maio 2014.

LORENZET, D.; CARPENEDO, V. D. Multiculturalismo, intercultura e as políticas afirmativas. Disponível em: <http://www.ucs.br/etc/conferencias/index. php/anpedsul/9anpedsul/paper/viewFile/95 1/398 >. Acesso em: 10 Out. 2013.

NEIRA, M. G. Educação Física: desenvolvendo competências. São Paulo: Phorte, 2003.

NERI, J. P. O negro na historia do Brasil: uma luta pela a conquista dos direitos. Disponível em: < www.palmares.gov.br/wpcontent/.../O-negro-na-historia-do-

Brasil.pdf>. Acesso em: 10 Fev. 2013.

OLIVEIRA, Leila Maria. 0 ensino da história e cultura afro-brasileira e a Educação física: um estudo sobre o currículo vivido em Santo André. São Paulo, 2012. Dissertação (Mestrado em Educação) - Pontifícia Universidade Católica de São Paulo.

PLATT, A. D. As políticas da "nova direita": políticas sociais inclusivas e políticas econômicas excludentes. Disponível em: $<$ <http:// cacphp.unioeste.br/projetos/gpps/midia/.../10a 
dreanadulcinaplatt.pd $\gg$. Acesso em: 10 Out.

2013.

SILVA, M. L. Miscigenação e Biopolítica no Brasil. Revista Brasileira de História \&

Ciências Sociais, v.. 4, n. 8, dez. 2012.

SÃO PAULO. Caderno do Aluno: Educação Física 6a Série/7ạ Ano. v. 1. São Paulo: SEESP, 2013a.

SÃO PAULO. Caderno do Aluno: Educação Física 8a Série/9a Ano. v. 1. São Paulo: SEESP, 2013b.

SÃO PAULO. Caderno do Professor: Educação Física 6a Série/7a Ano. Vol. 1. São Paulo: SEESP, 2013c.

SÃO PAULO. Caderno do Professor: Educação Física 8a Série/9a Ano. Vol. 1. São Paulo: SEESP, 2013d.

Recebido para publicação em 11/08/2014 Aceito em 05/09/2014 